\title{
Determination of factors affecting the quality of life in children with asthma
}

\author{
Yağmur Şancı Çekingen¹, Lale Ayşegül Büyükgönenç ${ }^{2}$ \\ ${ }^{1}$ Department of Nursing, Aclbadem Mehmet Ali Aydinlar University, Faculty of Health Sciences, Istanbul, Turkey \\ ${ }^{2}$ Department of Nursing, Cyprus Science University, Faculty of Health Science, Girne, Northern Cyprus
}

\begin{abstract}
Objectives: This study has been conducted in order to determine the factors affecting the quality of life in children with asthma.

Methods: The study sample consisted of 103 children (aged 7-16). Data has been collected using sociodemographic questionnaire and Pediatric Asthma Quality of Life Questionnaire (PAQLQ) through face to face interviews.

Results: Seventy-eight point six percent of the children's daily activities were affected due to asthma. Evaluating the sub-groups mean scores of the life quality of the children; the highest mean score was in the symptoms group. The activity limitation sub-group mean score was significantly decreased with the increase of the number of people living in the house and other siblings having asthma too. The symptom sub-groups mean scores of the children that are exposed to smoke and psychological factors and which state that their daily activities are being affected was lower. The emotional function sub-groups mean score of the children that are exposed to psychological factors was significantly decreased. The scale total mean score of the children with sensitivity to cockroach and psychological factor stimulant was lower $(p<0.05)$.

Conclusions: It's been suggested that the stimulants which trigger the symptoms, asthma disease, accurate and effective medication treatment and self-care should be taught to the child and the family; home care continuity should be ensured and arranging the environment to reduce the child's connection with the allergens that could trigger the asthma attack is necessary.

Keywords: Asthma, children, quality of life, risk factors, nursing
\end{abstract}

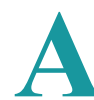
sthma, which is thought to affect about 300 million people worldwide, is an increasingly common disease with increasing morbidity in all age groups. It is one of the most common chronic diseases in childhood. Global rate of asthma is $1-18 \%$ according to the Global Initiative for Asthma (GINA) 2016 report [1]. It is estimated that approximately 250000 people die annually due to asthma. This figure is expected to reach 400 million people by 2025 .
Asthma is a multifactorial disease. Environmental factors (allergens, smoking, infections, air pollution) and personal factors (genetics, sex, obesity) play a role in the emergence of this disease together. Genetic factors are the most influential factors for the development of asthma. The factors that lead to asthma exacerbations are generally environmental factors. The effects of genetic and environmental risk factors are chronic inflammation of the airways. Structural 
changes, bronchial hyperactivity, and symptoms appears after airway obstruction along with inflammation $[1,2]$.

Individuals with chronic illness have difficulties in carrying out their daily and self-care activities. In additon, they may have to go to the hospital repeatedly, suffer from side effects of the medications or live dependent to a medical device. These conditions impair the physical and psychological well-being of the chronically ill individuals. The children and adolescents with chronic illness have lower rates of performing of daily activities and physical activities compared to healthy children [3]. The results of the studies on the subject show that asthma affects children's daily lives, limits their activities and has negative effects on their feelings [4].

The children with asthma may sometimes experience feelings as guilt, loneliness, fear, anxiety and disappointment. Their school life, daily life and especially sports activities may be interrupted by the disease [5]. The most important clinical signs of asthma are shortness of breath, coughing, wheezing, being affected by cigarette smoke or other environmental irritants, weather changes, attacks of viral infections, sleep disturbances and adverse effects of treatment applications, are the most important factors which affect the quality of life of asthmatic children [6]. It is stated that asthma patients are at high risk of respiratory illnesses in three months of the year (January, May, September) due to allergenic substances (domestic and outdoor) and environmental pollutants such as ozone and carbon monoxide. Increased air pollution in winter, more respiratory tract infections, increased pollen levels in the spring cause an increase in asthma symptoms. The daily life of children with asthma is negatively affected by the signs of coughing and shortness of breath due to these causes. In addition, the participation of children with asthma in sporting activities is often prevented by their parents and they are not allowed to participate in school physical education classes to run, to run and play. School absences occur especially in the winter months because of the exarcebation of symptoms. It has also been reported that school failure due to illness and school failure in asthmatic children as a result of occasional need to go to the hospital. It is necessary that children with asthma are approached holistically during the treatment phase and the quality of life must be evaluated and considered when these factors are taken into account [7].

Nowadays, the increase in the desire for healthy life, the increase in lifespan because of the developments in every fields, especially in the health field have caused the expectation of continuing a quality life in chronic diseases $[8,9]$. It is known that adult individuals with low quality of life experienced more life quality problems in their childhood and focus on quality of life at early ages declines the quality of life problems in adulthood [10]. Therefore, it is important to strengthen the child by early identification of the problems that may negatively affect the quality of life of children with chronic diseases. Asthma management prevent the development of the symptoms of asthma help asthmatic children and their families to maintain their daily life activities in good quality [9, 11]. For a quality of life, children with asthma and their parents are taught with the cause of asthma, the stimulants that initiate the disease, the prevention of acute attacks, asthma symptoms and treatment, care principles and follow-ups, thus they can manage their disease.

\section{METHODS}

This descriptive study was conducted between March 28 and May 28, 2016 at Pendik Training and Research Hospital-Pediatric Chest Diseases Polyclinic and Child Allergy-Immunology Polyclinic of Marmara University (Istanbul/Turkey).

\section{Participants}

The sample consisted of the children who applied to the policlinic and who were followed up for asthma. Selection criteria for the sample: in the 7-17 age group, at least 3 months since the diagnosis of asthma [12], no communication barriers of the children and their parents, and no other chronic disease. In total, 467 children with asthma who applied to the outpatient clinic between March 28 and May 28, 2016 in accordance with the selected sample selection criteria were included. In this study, a purposive sample was addressed, the data were collected on different days of the week. Patients who did not meet the sampling selection criteria were excluded from the study and 103 children from 467 asthmatic children who were 
reached were included in the sample.

\section{Ethical Considerations}

Written permission from the hospital and ethical consent from the ethics committee were obtained prior to the conduct of this study. The childrens' parents were informed of the aim and protocol of this study and both their written and oral consent were obtained. In the study, the related ethical principles of the Informed Consent Policy, Volunteer Policy, and Privacy Protection Policy were fulfilled.

\section{Data Collection}

Data has been collected using socio-demographic questionnaire and Pediatric Asthma Quality of Life Questionnaire (PAQLQ) through face to face interviews. The sociodemographic questionnaire form consists of 37 questions prepared by the researcher based on the relevant literature. In the sociodemographic questionnaire, the questions for the parameters such as the age of the child, gender, parents' ages, educational status, income level, as well as questions about the severity of asthma, the time after asthma diagnosis, and the number of hospitalizations which were considered to affect quality of life were included.

Pediatric Asthma Quality of Life Questionnaire (PAQLQ): The scale is a disease and age-specific quality of life scale, was developed by Juniper et al. [13] in 1996 to measure the physical, mental and social disorders of asthmatic children in the 7-17 age group. The general internal consistency coefficient of the scale was 0.85 , the emotional function score was 0.80 , the activity restriction score was 0.84 . The scale consists of 23 questions collected under three areas:

1. Field: Emotional function score (5, 7, 9, 11, 13, $15,17,21$. questions)

2. Field: Activity limitation score $(1,2,3,19$. ve 22. questions)

3. Field: Symptoms score $(4,6,8,10,12,14,16$, 18, 20, 23. questions)

Every question on the scale was equally weighted. The results were described as "average score per question" for both total quality of life and each field. Thus, four points including three field scores and total scale points are obtained [14]. Both the total quality of life score and the field scores of the scale vary between 1 and 7 . Thus, the results of both the five- question area and the ten-question area were described as a score in the range of 1 to 7 . In the field of emotional function, mimimum score was 8 and maximum score was 56 while the minimum point was 5 and maximum point was 35 in the field of activity restriction. The minimum score was 10 and maximum was 70 in the field of symptoms when the minimum total life quality score was 23 and maximum total life quality score was 161 . The total quality of life score was calculated from the mean score of all the questions. The highness of mean scores indicated that the quality of life was good.

The Turkish validity and reliability study of the Quality of Life Scale of Asthmatic Children was conducted by Yüksel et al. [14] in 2019. The Cronbach Alpha values of 122 children with asthma were 0.86 for emotional function field, 0.80 for activity restriction field and 0.90 for symptoms field [14]. In this study, Cronbach Alpha values were 0.82 for emotional function, 0.60 for activity restriction, 0.86 for symptoms and 0.90 for total score.

\section{Statistical Analysis}

The data were statistically analysed with SPSS 21.0 (Statistical Package for Social Sciences) program. Number, percentage, correlation, importance test of the difference between two means in two-some groups, Mann-Whitney U test, Kruskal-Wallis analysis for groups with 3 or more, and in the case that the $p$ value results less than 0.05 in the analysis of multigroups; in order to determine the group which creates the difference, the Post-Hoc tests such as Independent Samples t test with Bonferroni correction and MannWhitney U test with Bonferroni correction were used to evaluate the data. The difference between the two groups was considered significant when $p<0.05$ in the $95 \%$ confidence interval for all statistical analyses.

\section{RESULTS}

Seventy-three point eight percent of the children were in the age group of 7-11 years, $26.2 \%$ were in the age group of 12-17 years, the average age was $9.8 \pm$ 2.6. $51.5 \%$ of them are girls. It was found that $99 \%$ of the children continued their education when one child left the school in high school. Thirty-six point nine percent of the parents stated that the children 


\section{Table 1. Parents' opinions for the being affected status of children's daily activities by asthma and affected areas}

\begin{tabular}{|ccc}
\hline Opinions & Number & $\%$ \\
\hline Being affected status of daily activities & & \\
\hline Yes & 81 & 78.6 \\
\hline No & 22 & 21.4 \\
\hline Affected fields* & 67 & 65.0 \\
\hline Inability to play game & 47 & 45.6 \\
\hline Irregular attendance to courses & 45 & 43.7 \\
\hline Intermittent sleep & 26 & 25.2 \\
\hline Decreased appetite & 13 & 12.6 \\
\hline Inability to run fast & 9 & 8.7 \\
\hline Inability to enter physical education courses & 7 & 6.8 \\
\hline Increased appetite & & \\
\hline
\end{tabular}

*The parents who indicated that their children's daily activities were affected by the disease, responded more than once to the affected fields.

experienced failures in their courses. In $6.8 \%$ of children, the duration after the diagnosis of asthma was 3-11 months, $1-3$ years in $30.1 \%$ of them , 4-6 years in $35 \%$ of them, $7-9$ years in $19.4 \%$ of them and over 10 years $8.7 \%$ of them.

Thirty-eight point eight percent of the children were hospitalized because of asthma, $85 \%$ of them were hospitalized 1-5 times. When asthma excretion cases were examined, it was determined that $75.7 \%$ of them had asthma attacks, $92.0 \%$ of these children had 1-5 attacks. When the occurrence rate of asthma in children was analyzed, $74.8 \%$ of them experienced less than once a week, $5.8 \%$ of them experienced a few times a week, $15.5 \%$ of them experienced every day and, $3.9 \%$ of them continuously experienced. When $90.3 \%$ of parents stated that their children used continuous medication for asthma treatment, the rate of regular users of medication was found as $78.6 \%$. When parents were asked for feeling differences of their asthmatic children from their peers, $68.9 \%$ of them stated that they did not feel any difference. The children who feel themselves different from their peers stated these differences as:attending to the school, participating in sports activities, being with pets, going to the hospital and using medication.

In $67 \%$ of the children, asthma symptoms were triggered by cigarette smoke, the asthma symptoms were triggered by house dust mites in $66 \%$ of them, the asthma symptoms were triggered by pollen in
$57.3 \%$ of them, the asthma symptoms were triggered by air pollution in $46.6 \%$ of them, the asthma symptoms were triggered by animals in $11.7 \%$ of them, the asthma symptoms were triggered by psychological factors in $11.7 \%$ of them, the asthma symptoms were triggered by humidity in $9.7 \%$ of them, the asthma symptoms were triggered by mold in $5.8 \%$ of them and the asthma symptoms were triggered by cockroach in $4.9 \%$ of them. In addition to these factors, $40.8 \%$ of the parents stated that perfume odor, detergent odor, respiratory tract infection, grass odor, bleach odor, wool, hot air, acidic drinks and strawberry were among the things that trigger asthma symptoms in children.

Eighty-six point four percent of the parents were mothers, $13.6 \%$ of them were fathers. $96.1 \%$ of the parents stated that they were married and 3.9\% stated that they were divorced. When the ages of the mothers were analyzed, $27.0 \%$ of them were between the ages

\section{Table 2. Children's quality of life scale average} scores

\begin{tabular}{lcc}
\hline Fields & Min-Max & $\mathbf{X} \pm \mathbf{S S}$ \\
\hline Emotional function & $8-56$ & $42.94 \pm 11.05$ \\
Activity limitation & $5-35$ & $25.90 \pm 5.50$ \\
Symptoms & $10-70$ & $52.68 \pm 12.75$ \\
Total Score & $23-161$ & $121.53 \pm 25.29$ \\
\hline
\end{tabular}


of $30-34,33.7 \%$ of them were between the ages of $35-$ 39. Seventy-three point eight percent of them were primary school graduates while $86.4 \%$ of them were unemployed. When the ages of the fathers were analyzed, $28.6 \%$ of them were between the ages of 40 44 and over 50 , and $96.1 \%$ of them were employed. $94.2 \%$ of the parents lived in the district. Eighty-two point five percent of them stated that their income was equal to their expenses, $14.6 \%$ of them stated that their income below their expenses, $95.1 \%$ of them had social security. Fifty-seven point three percent of the parents had 4 or less households in their houses, $40.8 \%$ of them had 5-7 households in their houses. The mean number of people living in the house was $4.5 \pm 1.19$. Eighty-nine point three percent of the parents stated that they had children other than those who were brought to the polyclinic, $74.8 \%$ of them stated that they had other children, $76.7 \%$ stated that their other children did not have asthma. Ten point seven percent of the mothers and $45.6 \%$ of the fathers were smokers. Eighty-nine point three percent of the parents stated that they got training for asthma, $92.2 \%$ of them were educated about asthma-triggering factors. In Table 1, the opinions of the parents who participated in the study on their children's daily activities due to illness and the affected areas were given.

When the characteristics of the home environments of the asthmatic children were analyzed, $96.1 \%$ of the parents stated that they did not smoke in their homes. Eighty-eight point three percent of the parents stated that they used combi boilers to heat their homes, $11.7 \%$ of them used charcoal sofas. $88.3 \%$ of them had no pets, $11.7 \%$ of them had pets. $69.9 \%$ of them stated that there was no humidity problems in

Table 3. Life quality scale points according to stimulating features that start asthma symptoms in children

\begin{tabular}{lllllllll}
\hline Features & \multicolumn{2}{c}{$\begin{array}{c}\text { Emotional } \\
\text { function }\end{array}$} & $\begin{array}{c}\text { Activity } \\
\text { limitation }\end{array}$ & \multicolumn{2}{c}{ Symptoms } & \multicolumn{2}{c}{ Total } \\
\cline { 2 - 9 } & $\bar{x}$ & SS & $\bar{x}$ & SS & $\bar{x}$ & SS & $\bar{x}$ & SS \\
\hline
\end{tabular}

Cigarette smoking

\begin{tabular}{rcccccccc} 
Yes $(\mathrm{n}=69)$ & 41.95 & 10.94 & 25.40 & 5.78 & 50.46 & 13.80 & 117.82 & 26.68 \\
\hline No $(\mathrm{n}=34)$ & 44.50 & 11.04 & 26.58 & 4.74 & 55.91 & 10.13 & 127.00 & 21.11 \\
$t$ test & 1.106 & 1.032 & 2.265 & 1.895 \\
$p$ value & 0.271 & 0.304 & $\mathbf{0 . 0 2 6}$ & 0.062
\end{tabular}

Psychological factors

\begin{tabular}{|c|c|c|c|c|c|c|c|c|}
\hline Yes $(n=12)$ & 36.33 & 12.36 & 22.91 & 6.31 & 40.41 & 15.63 & 99.66 & 31.67 \\
\hline No $(\mathrm{n}=91)$ & 43.64 & 10.57 & 26.17 & 5.26 & 53.82 & 11.75 & 123.64 & 23.07 \\
\hline Mann-Whitney U test & \multicolumn{2}{|c|}{346.000} & \multicolumn{2}{|c|}{384.500} & \multicolumn{2}{|c|}{276.500} & \multicolumn{2}{|c|}{299.000} \\
\hline$p$ value & \multicolumn{2}{|c|}{0.040} & \multicolumn{2}{|c|}{0.096} & \multicolumn{2}{|c|}{0.006} & \multicolumn{2}{|c|}{0.011} \\
\hline \multicolumn{9}{|l|}{ Cockroaches } \\
\hline Yes $(n=5)$ & 46.20 & 8.13 & 29.0 & 3.04 & 65 & 4.15 & 141.00 & 7.74 \\
\hline No $(n=98)$ & 42.62 & 11.12 & 25.6 & 5.51 & 51 & 12.86 & 119.82 & 12.86 \\
\hline Mann-Whitney U test & \multicolumn{2}{|c|}{205.000} & \multicolumn{2}{|c|}{139.500} & \multicolumn{2}{|c|}{72.500} & \multicolumn{2}{|c|}{109.500} \\
\hline$p$ value & \multicolumn{2}{|c|}{0.539} & \multicolumn{2}{|c|}{0.105} & \multicolumn{2}{|c|}{0.008} & \multicolumn{2}{|c|}{0.038} \\
\hline
\end{tabular}


their homes, $30.1 \%$ of them stated that they had dampness in their homes, $93.2 \%$ of them stated that their houses catched the sun, $98.1 \%$ stated that they had a home ventilation. Ninety-nine percent of the parents stated that they took measures against asthma stimulants in their homes.

The children's quality of life of asthmatic children scale was found to be $121.53 \pm 25.29$. When mean subgroup scores were evaluated, the lowest mean score was found in the field of activity restriction, it was followed by subgroups of emotional function and symptoms (Table 2).

When the quality of life scale scores were analyzed according to the sociodemographic characteristics of the children, it was found that age, gender, general school unsuccess did not affect the quality of life. No significant effect on the quality of life of the child was observed when the scores of the quality of life scale were taken into account according to the disease characteristics of the child such as the number of asthmatic attacks, the number of hospitalizations due to asthma, the frequency of asthma symptoms. Seventy-nine percent of the children regularly used their medications. The stimulants such as house dust mites, pollen, air pollution, animal, humidity and mold were found to have no effect on the children's quality of life when the stimuli that triggered asthma symptoms were analyzed.

The stimulus such as cigarette smoke, psychological factors, cockroaches found to have different effects on the quality of life of the children

Table 4. Quality of life scale scores according to children's parents' descriptive characteristics

\begin{tabular}{|c|c|c|c|c|c|c|c|c|}
\hline \multirow[t]{2}{*}{ Introducing features } & \multicolumn{2}{|c|}{$\begin{array}{l}\text { Emotional } \\
\text { function }\end{array}$} & \multicolumn{2}{|c|}{$\begin{array}{c}\text { Activity } \\
\text { limitation }\end{array}$} & \multicolumn{2}{|c|}{ Symptoms } & \multicolumn{2}{|c|}{ Total } \\
\hline & $\bar{x}$ & SS & $\bar{x}$ & SS & $\bar{x}$ & SS & $\bar{x}$ & SS \\
\hline \multicolumn{9}{|l|}{ Number of people living at home } \\
\hline 4 people and below $(n=59$ & 43.18 & 10.31 & 26.71 & 5.07 & 53.67 & 11.45 & 123.57 & 23.19 \\
\hline $5-7$ people $(n=42)$ & 43.21 & 11.17 & 24.85 & 5.76 & 51.14 & 14.42 & 119.21 & 26.61 \\
\hline 8 people or more $(n=2)$ & 22.50 & 13.43 & 18.50 & 0.707 & 34.00 & 5.65 & 75.00 & 7.07 \\
\hline Kruskal-Wallis analysis & \multicolumn{2}{|c|}{4.053} & \multicolumn{2}{|c|}{6.311} & \multicolumn{2}{|c|}{3.895} & \multicolumn{2}{|c|}{4.993} \\
\hline$p$ value & \multicolumn{2}{|c|}{0.132} & \multicolumn{2}{|c|}{0.043} & \multicolumn{2}{|c|}{0.143} & \multicolumn{2}{|c|}{0.082} \\
\hline
\end{tabular}

Asthma in other children

\begin{tabular}{|c|c|c|c|c|c|c|c|c|}
\hline Yes $(n=26)$ & 42.38 & 13.13 & 23.50 & 5.69 & 49.73 & 14.19 & 115.61 & 29.09 \\
\hline No $(\mathrm{n}=77)$ & 42.93 & 10.25 & 26.57 & 5.20 & 53.11 & 12.44 & 122.62 & 23.76 \\
\hline Mann-Whitney U test & \multicolumn{2}{|c|}{959.000} & \multicolumn{2}{|c|}{680.000} & \multicolumn{2}{|c|}{878.500} & \multicolumn{2}{|c|}{882.500} \\
\hline$p$ value & \multicolumn{2}{|c|}{0.752} & \multicolumn{2}{|c|}{0.015} & \multicolumn{2}{|c|}{0.352} & \multicolumn{2}{|c|}{0.368} \\
\hline \multicolumn{9}{|l|}{ Mom's smoking status } \\
\hline Yes $(n=11)$ & 43.63 & 11.39 & 29.54 & 3.85 & 55.00 & 11.13 & 128.18 & 23.82 \\
\hline No $(n=92)$ & 42.56 & 10.98 & 25.26 & 5.44 & 51.75 & 13.09 & 119.58 & 25.25 \\
\hline Mann-Whitney U test & \multicolumn{2}{|c|}{485.000} & \multicolumn{2}{|c|}{279.000} & \multicolumn{2}{|c|}{449.500} & \multicolumn{2}{|c|}{400.500} \\
\hline$p$ value & \multicolumn{2}{|c|}{0.822} & \multicolumn{2}{|c|}{0.015} & \multicolumn{2}{|c|}{0.546} & \multicolumn{2}{|c|}{0.260} \\
\hline
\end{tabular}


Table 5. Quality of life scale scores according to influence of daily activities of the child due to illness

\begin{tabular}{rccccccccc}
\hline Daily activity affects status & \multicolumn{2}{c}{$\begin{array}{c}\text { Emotional } \\
\text { function }\end{array}$} & \multicolumn{2}{c}{$\begin{array}{c}\text { Activity } \\
\text { limitation }\end{array}$} & \multicolumn{2}{c}{ Symptoms } & \multicolumn{2}{c}{ Total } \\
\cline { 2 - 10 } & $\bar{x}$ & SS & $\bar{x}$ & SS & $\bar{x}$ & SS & $\bar{x}$ & SS \\
\hline Yes $(\mathrm{n}=81)$ & 42.40 & 10.67 & 25.43 & 5.77 & 50.81 & 13.50 & 118.65 & 25.98 \\
No ( $=22)$ & 44.22 & 12.22 & 27.13 & 3.95 & 57.59 & 8.82 & 128.95 & 20.95 \\
Mann-Whitney U test & 727.000 & 752.500 & 643.000 & 687.000 \\
$p$ value & 0.186 & 0.264 & $\mathbf{0 . 0 4 6}$ & 0.101 \\
\hline
\end{tabular}

unlike other stimuli. As indicated in Table 3, the children who ecountered with psychological factors, who exposed to cigarette smoke that initiated asthma symptoms had a significantly lower mean symptom subgroup score $(p<0.05)$. The mean score of emotional function subgroup in children who were encountered with psychological factors was also found to be low $(p<0.05)$. In children who were exposed to cockroach stimulus, psychological factors, the total score of the quality of life scale was found statistically significantly lower $(p<0.05)$.

The age of parent, educational status, employment status, income status and the status of getting education about asthma were found to have no effect on the quality of life of the child. As shown in Table 4 , the difference between the mean scores of the activity restriction subscale was found to be statistically significant $(p<0.05)$. In a further analysis to determine which subscale determines the difference, the difference was found to be due to the number of people living in the homes between 5-7 and 8 and above $(p=0.0027)$. It was found that no significant difference between the other subscales ( $p$ $=0.0167)$. The children who had a sibling with asthma and a mother who did not smoke, were found to have a low mean score for activity restriction subscale $(p<$ $0.05)$.

When the mean score of the quality of life scale and subscale scores were evaluated according to the state of daily activities, the mean total score and subgroup score of the children who did not affected by daily activities were found higher (Table 5). In children who were affected by daily activities due to disease, the mean symptom subscale score was significantly lower $(p<0.05)$.

When the quality of life scale scores were evaluated according to the characteristics of the home environment, it was found that the heating instrument (combi / stove), humidity status, the status of getting sunlight and house ventilation status had no significant effect on the quality of life of the child. The mean score of emotional function subscale of children with asthma who lived with pets was found significantly higher $(p<0.05)$.

\section{DISCUSSION}

The mean total quality of life scale score was found to be higher than the other studies $[6,9,15,16]$. This can be explained by the fact that most of the parents in the study were trained for asthma (89.3\%), they could shape their children's daily life activities in this direction.

Although it was not statistically significant, it was determined that the quality of life was negatively affected by inreased time after asthma diagnosis. This finding is also similar to the literature [4, 9, 17], suggests that the children who live with a chronic illness for a long time need more support.

In asthmatic children, there are many factors that trigger asthma. Among these factors, exposure to cigarette smoke is one of the most important factors. In this study, a statistically significant difference was found between the mean score of the symptoms subscale of the children who exposed to cigarette 
smoke and the mean score of the symptoms subscale of the children who did not exposed to cigarette smoke $(p<0.05)$. It is known that smoking decrease the quality of life of asthmatic children [4, 6, 17-19]. In the studies, it was found that $1 / 3$ of asthmatic children are affected by smoking at home, cigarette smoke affects total and specific allergen levels and skin tests for allergens, allergic symptoms are correlated with parental smoking, maternal smoking is an important risk factor for asthma, children who have smoker mothers have significantly higher levels of asthma than mothers who did not smoke [20-24]. This finding of our study also supports that cigarette smoke is an important stimulus that induces asthma in children and adversely affects the quality of life. In this study, it was also found that $10.7 \%$ of the mothers and $45.6 \%$ of fathers were smokers. Although not statistically significant, asthmatic children with a father had a lower quality of life score than non-smokers with asthma ( $p>0.05)$. In the study of Gümüş et al. [9], there was no significant relationship between smoking in the family and the quality of life. In a study by Murray et al. [24], the symptoms of asthma in asthmatic children with smoker mothers were found to be much higher than in asthmatic children with mothers who did not smoke.

In many studies, smoking habit of the mother was related to the child's asthma symptoms $[4,6,17,18$, $20-22,24]$. In this study, it was found that the children who had smoker mothers, had higher mean activity restriction subscale scores and the difference was statistically significant $(p<0.05)$. This finding suggests that smoker mothers do not smoke in the presence of their children, therefore the quality of life of the child is not adversely affected.

In $11.7 \%$ of the children in our study, psychological factors were found to initiate asthma attacks. The children who exposed to psychological factors were significantly lower mean scores in emotional function and symptom subscale and total quality of life scale compared to the children who stated that psychological factors did not initiate an asthma attack $(p<0.05)$. It was stated that regular medication, frequent hospitalizations, asthma attacks, the restriction of activities and falling back from from school and courses are stressful factors on asthmatic children $[5,25]$. Our findings support that the children who can cope with psychological factors can control asthma attacks, thus their quality of life is also positively affected.

Four point nine percent of the children were affected by cockroach stimulus that initiate asthma attacks. A statistically significant difference was found between the mean symptom subscale and quality of life total scores of the children whose asthma symptoms were triggered by cockroaches and the mean symptom subscale and quality of life total scores of the children whose asthma symptoms werenot affected by cockroaches $(p<0.05)$. There are studies that found positive correlation between cockroach allergen and asthma symptoms [20,26]. The children who are affected by cockroach stimuli are rare, but our results are similar to the results of the other studies on the subject, the mean total quality of life and symptom subscale scores were found as high.

When the effect of the number of people living with the asthmatic child in the home on the quality of life, it was determined that an increase the number of people living in the household decrease the mean total quality of life scale and the subscale scores. The difference between the number of people living in the home and the activity restriction subscale scores was found as statistically significant $(p<0.05)$. This significance in the mean activity restriction subscale score suggests that other people in houses also obey the restrictions for the children in order to avoid symptoms of asthma, the absence of asthma symptoms in spite of increased number of people may be related with this. According to the similar studies in the literature, it was found that the number of people living in the home has no effect on the the quality of life of an asthmatic child [6,9].

It is known that pets exacerbate symptoms in asthmatic patients. In this study, $11.7 \%$ of the children with asthma were found to have pets (birds) in their homes. When the mean quality of life and the mean subgroup scores of the children living with pets were analyzed, it was found that the mean scores were higher compared to the children living without pets, the mean score of the emotional function subgroup was also statistically significant $(p<0.05)$. Kurt et al. [23] found that respiratory symptoms were more common in the individuals who live near the animal shelter. Tamay et al. [27] also showed that the presence of animals in the home increases asthma findings. Demirci and Güler [6] found that there is no 
relationship between pets and quality of life at home. The positive effects of pets on the individuals with chronic diseases are stated in the literature [28]. In our study, the children living with pets had higher mean quality of life scores, especially mean emotional function score, this condition may be explained by the fact that the symptoms of asthma in children were not very severe and pets have the positive emotional effects on children.

Asthma affects children's daily lives and activities in different aspects. In our study, $78.6 \%$ of the children were found to be affected in terms of the daily activities due to disease. The most affected activity by asthma was found as game activity with $65 \%$. Play is an important part of the child's life and is known to be a valuable contribution to the children's physical, cognitive and psychosocial development. When the other activities that were affected by asthma were analyzed, it was found that $45.6 \%$ of them could not attend classes regularly, $43.7 \%$ of them had had intermittent sleep, $25.2 \%$ of them had decreased appetite, $12.6 \%$ of them could not run fast and $8.7 \%$ did not attend physical education classes. In the study of Özkaya et al. [4], three activities of the children were found to be affected by the asthma, they are running (66\%), playing football (36\%) and climbing up stairs (27\%). Reichenberg et al. [29] studied with asthmatic children living in Sweden, it was found that running (74\%), gymnastics (30\%) and climbing (26\%) are affected. In the literature, the most affected activity is running, but gaming activity was fund as the most affected activity in this study, this condition may be related with the families' protective, limitating manners.

Our this study determined that the children with asthma who stated that their daily activities were affected compared to the children had lower mean total quality of life scale and subscale scores compared to the children with asthma who stated that their daily activities were not affected. There was a statistically significant difference between the mean symptom subscale score of the children who had affected daily activities by asthma and the mean symptom subscale score of the children who did not have affected daily activities by asthma $(p<0.05)$. It was found that the quality of life of children who could play games, regularly attended their courses, did not lose their appetite and run fast was higher, although this difference was not statistically significant. These results support that alterations in daily activities due to the disease negatively affect the quality of life of the children.

\section{Limitations}

The results can not be generalized because the study was carried out only in one institution. The results reflect self-declarations of the children and their parents.

\section{CONCLUSION}

It was observed that the quality of life of the children with asthma is affected by symptoms such as wheezing, shortness of breath, chest thightness and coughing attacks. In this direction, the nurse should maintain continuity of home care by teaching stimulants that initiate symptoms, asthma disease, appropriate and effective drug treatment, self-care to the children and their families. The protective attitude towards the child should be prevented and the child's activities such as play, school, sports should be maintained in accordance with the program determined by the health professional. To inhibit psychological factors' effects such as increasing asthma symptoms and affecting quality of life in a negative way, the autonomy of the child should be maintained to deal with his or her own disease and age specific approach should be applied. When pediatric nurses detect allergens, they should help the family to arrange the environment to reduce the child's association with the allergens that can trigger the seizure.

\section{Conflict of interest}

The authors disclosed no conflict of interest during the preparation or publication of this manuscript.

\section{Financing}

The authors disclosed that they did not receive any grant during conduction or writing of this study.

\section{Acknowledgements}

We are very grateful to the adolescents who participated in the study and shared their experiences of daily life with asthma. 


\section{REFERENCES}

1. Global Strategy for Asthma Management and Prevention Global Initiative for Asthma (GINA). 2016.

2. Barners PJ. Asthma. In: Loscalzo J, ed., Harrison's Pulmonary and Critical Care Medicine. New York: The McGraw-Hill Companies, Inc., 2010: pp.60-78.

3. Durualp E, Kara FN, Yılmaz V, Alaybeyoğlu K. [Comparison of life qualities according to the views of children and parents with and without chronic disease]. Ankara Üniversitesi Tip Fakültesi Mecmuası 2010;63:55-63. [Article in Turkish]

4. Özkaya E, Sancar Ö, Dündaröz MR. [The effect of risk factors on quality of life in childhood asthma]. Bezmialem Science 2014;1:52-7. [Article in Turkish]

5. Sandberg S, Paton JY. Ahola S, McCann DC, McGuinness D, Hillary CR, et al. The role of acute and chronic stress in asthma attacks in children. Lancet 2000;356:982-7.

6. Demirci E, Güler N. Astımlı çocuklarda yaşam kalitesi ve etkileyen bazı faktörler. T.C. Cumhuriyet Üniversitesi Sağlık Bilimleri Enstitüsü. Yüksek lisans tezi (Thesis). 2011.

7. Juniper EF, Guyatt GH, Feeny DH, Ferrie PJ, Griffith LE, Townsend M. Measuring quality of life in the parents of children with asthma. Qual Life Res 1996;5:27-34.

8. Göker Z, Aktepe E, Kandil S. [Self-esteem and quality of life in children and adolescents with attention deficit hyperactivity disorder]. Yeni Symposium 2011;49:209-16. [Article in Turkish] 9. Gümüş S, Kelekçi S, Yolbaşı İ, Gürkan F. [Assesment of quality of life in children with asthma]. J Clin Anal Med 2012;3:178-81. [Article in Turkish]

10. Eiser C, Morse R. Quality-of-life measures in chronic diseases of childhood. Health Technol Assess 2001;5:1-157.

11. Ergin D, Yüksel H, Şen N, Eser Ö, Özmen D. Astımlı çocuklar ile sağlıklı çocukların ve ailelerinin yaşam kalitesinin karşılaştırılması ve yaşam kalitesini etkileyen faktörlerin incelenmesi. 2. Sağlikta Yaşam Kalitesi Sempozyumu. Manisa, Turkey, 2007; page 75 .

12. Ekici B, Cimete G. Effects of an asthma training and monitoring program on children's disease management and quality of life. Turk Thorac J 2015;16:158-65.

13. Juniper EF, Guyatt GH, Feeny DH, Ferrie PJ, Griffith LE, Townsend M. Measuring quality of life in children with asthma. Qual Life Res 1996;5:35-46.

14. Yüksel H, Yilmaz O, Kirmaz C, Eser E. Validity and reliability of theTurkish translation of the Pediatric Asthma Quality of Life Questionnaire. Turk J Pediatr 2009;51:154-60.

15. Bozkurt G, Yildız S. [ The effect of education given to the school children with asthma about management of the disease, on their quality of life]. İstanbul Üniversitesi F.N.H.Y.O. Dergisi 2004;13:101-13. [Article in Turkish]

16. Boran P, Tokuç G, Pişgin B, Oktem S. Assessment of quality of life in asthmatic Turkish children. Turk J Pediatr 2008;50:18-
22.

17. Nogueira KT, Silva JR, Lopes CS. Quality of life of asthmatic adolescents: assessment of asthma severity, comorbidity, and life style. J Pediatr 2009;85:523-30.

18. Morkjaroenpong V, Rand CS, Butz AM, Huss K, Eggleston $\mathrm{P}$, Malveaux FJ, et al. Environmental tobacco smoke exposure and nocturnal symptoms among inner-city children with asthma. J Allergy Clin Immunol 2002;110:147-53.

19. Taminskiene V, Mukhopadhyay S, Palmer C, Mehta A, Ayres J, Valiulis A, et al. Factors associated with quality of life in children with asthma living in Scotland. Pediatr Pulmonol 2016;51:484-90.

20. Finkelstein JA, Fuhlbrigge A, Lozano P, Grant EN, Shulruff $\mathrm{R}$, Arduino KE, et al. Parent-reported environmental exposures and environmental control measures for children with asthma. Arch Pediatr Adolesc Med 2002;156:258-64.

21. Gilliland FD, Berhane K, McConnell R, Gauderman WJ, Vora H, Rappaport EB, et al. Maternal smoking during pregnancy, environmental tobacco smoke exposure and childhood lung function. Thorax 2000;55:271-6.

22. Karadağ B, Karakoç F, Kut A, Bakaç S, Dağlı E. [The effects of education on parental smoking behaviour of asthmatic children]. Bağımlılık Dergisi 2001;2:64-7. [Article in Turkish] 23. Kurt E, Metintas S, Basyigit I, Bulut I, Coskun E, Dabak S, et al. Prevalence and Risk Factors of Allergies in Turkey (PARFAIT): results of a multicentre cross-sectional study in adults. Eur Respir J 2009;33:724-33.

24. Murray AB, Morrison BJ. The effect of cigarette smoke from the mother on bronchial responsiveness and severity of symptoms in children with asthma. J Allergy Clin Immunol. 1986;77:57581.

25. Horner CC, Dula C, Garbutt JM, Gonzalez C, Deych E, et al. Daily global stress is associated with nocturnal asthma awakenings in school-age children. J Allergy Clin Immunol 2016;138:1196-9.e3.

26. Üzel A, Çapan N, Canbakan S, Yurdakul AS, Dursun B. Evaluation of the relationship between cockroach sensitivity and house-dust-mite sensitivity in Turkish asthmatic patients. Respir Med 2005;99:1032-7.

27. Tamay Z, Akçay A, Ones U, Guler N, Kılıç G, Zencir M. Prevalence and risk factors for allergic rhinitis in primary school children. Int J Pediatr Otorhinolaryngol 2007;71:463-71.

28. Cevizci S, Erginöz E, Baltaş Z. [A new assisted therapy concept for improving of mental health - animal assisted therapy]. Nobel Med 2009;5:4-9. [Article in Turkish]

29. Reichenberg K, Broberg AG. Quality of life in childhood asthma: use of the Paediatric Asthma Quality of Life Questionnaire in a Swedish sample of children 7 to 9 years old. Acta Paediatr 2000;89:989-95. 